\title{
Design Thinking: Governing Inter-Domain Thinking for Tackling the Anthropocene
}

\author{
Ashley Hall \\ Royal College of Art, London, UK
}

\begin{abstract}
This paper strikes an arc through C.P. Snow's influential 'Two Cultures' lecture at Cambridge University in 1959 through to Bruce Archer's assertion that design is the third culture of thinking in 1978 and positions how design thinking can contribute at a domain level to contemporary issues of the Anthropocene. After describing the separation of the three cultures of thinking, it considers different concepts for the third culture and how it may interact with the others. The core domain level practices of thinking cultures in the sciences, arts and humanities are explored and wroughting and wrighting is proposed for design. This contributes to a temporal model of knowledge production and exchange across domains. The value of governing and its application across domains is discussed and a proposal for a conceptual model of how inter-domain collaboration can address some of the problems of the Anthropocene is developed.
\end{abstract}

KEYWORDS: design theory, design practice, epistemology, philosophy of design, wroughting and wrighting

The Anthropocene (Waters et al. 2016) is a term coined to describe our current geological epoch which is defined by how humans have changed the world through our constructions and their resultant effects on the environment. One of the major issues of the Anthropocene is the question of how we can halt and reverse climate change, and how different domains and disciplines can collaborate to achieve this goal. Whilst there is a growing body of literature on design thinking from a range of design disciplines and other fields, less attention has been paid to the core practices of design thinking and how exploring the theoretical relationship of practices across different thinking cultures could contribute to tackling Anthropocene issues.

This propositional approach develops a theoretical arc by considering C.P. Snow's criteria for the third culture against Bruce Archer's suggestion of the core domain practices. Governing is evaluated in terms of its potential value to design and collaborative activity between the three thinking domains by reviewing historical examples, the link between mechanical governors, cybernetics and design. This leads to identifying an issue between knowledge types linked to thinking domains and how this may limit interdomain collaboration. A model is proposed for how the three domains can govern collaborations at a strategic level incorporating core practices that tackle wicked problems including those of the Anthropocene through temporal interactions of knowledge.

\section{The third culture}

There have been many potential points for the initiation of design thinking including Simon (1969), Archer (1978), and Cross (2011), however C.P. Snow's famous 'Two Cultures' Rede lecture at Cambridge University subsequently published as 'The Two Cultures and the Scientific Revolution' in 1959 serves as a good starting point for articulating a longer trajectory of thinking. Snow's proposed domain separation into the sciences and arts and humanities was controversial and adversarial commentary followed including that from Lionel Trilling and F.R. Leavis (1962) who wrote a counterargument critiquing the division of the domains of scientific and humanities thinking and asserting the importance of a unifying body of thought. Snow deals with a broad investigation of what a culture of thinking might be including a total refutation, and that there is 'only thinking' verses what he called the 'two thousand and two cultures' (Snow 1959, 66) identified as subcultures of the sciences or humanities. Collini (2013) in his introduction to the Two Cultures describes a key part of the conversation that:

...neither of these responses strictly rules out the possibility of their still being something distinctive shared by those activities which are referred to as 'the sciences', and not characteristic of those designated 'the humanities'. (Collini 2013, xlv) 
However, the most significant proposition for defining a culture of thinking is that:

At the heart of the two cultures is a claim about academic disciplines...But if the concept is to possess any continuing per- suasiveness it must offer an illuminating characteristic of the divide between two sorts of intellectual enquiry. (Collini 2013, xliii)

Collini also describes the social context of the time and that it was clear that scientists were displacing the upper middle-class literary elite as part of the establishment of a new domain, the impact was both social and scientific.

... neither the scientific system nor the traditional, is adequate for our potentialities, for the work we have in front of us, for the world in which we ought to begin to live. (Snow 1959, 64)

Here again we have another hint that a new form of thinking or a realignment of the two existing cultures is necessary, and finally Snow tackles the third culture:

It is probably too early to speak of a third culture already in existence. But I am now convinced that this is coming. When it comes some of the difficulties of communication will be softened: for such a culture has, just to do its job, to be on speaking terms with the scientific one. (Snow 1959, 71)

Following this thought Snow attempts to suggest a third field of enquiry (something often missed in the 1963 second edition of 'The Two Cultures') that may allow the emergence of thinking from organic community through to the nature of pre-industrial society or the scientific revolution. The hints here are loosely aimed at what we would now call the social sciences. Snow suggested several criteria for a new culture of thinking; that it should be able to illuminate the divide between the two existing cultures as an intellectual mode of enquiry, that it should be on speaking terms with Science, and finally we could surmise that is should be more than a bridge or negotiator between the socio-cultural and the scientifictechnical worlds containing both its own identifiable practices and modes of enquiry.

Although Snow is credited with proposing a third culture, Robin Darwin (Gooden 2015) had proposed the cross-domain partnership of design and engineering as early as 1945 following his work as secretary to the training committee of the Council for Industrial Design (CoID).

...the belief that art and the sciences should be mutually supportive, that in many branches of design one must be 'almost as much of an engineer as an artist'. (Gooden 2015, 92)

It is also worth mentioning Timmons (2007) who recounts the much earlier 1828 debate in the USA between two different cultures and of particular interest is his quotation from the Yale report which highlights these incompatible practices:

The man of science is often disposed to assume an air of superiority, when he looks upon the narrow and partial views of the mere artisan. The latter in return laughs at the practical blunders of the former. The defects in the education of both classes would be remedied, by giving them a knowledge of scientific principles, preparatory to practice. (Timmons 2007, 1)

Timmons goes on to describe how president elect Jackson's focus on the 'common man' led to a questioning of the higher education system that mirrors some of the social concerns illustrated by Snow one hundred and thirty year later and reminds us that the debate has yet to conclude. However, the social tensions described by Snow between the social elite and scientist are the inverse in the Yale report putting science above the common man rather than below high society. Moreover, Timmons and the Yale report do not address the potential for other thinking domains.

Further progress was made by Simon (1969) who separated design from the social sciences and set up an oppositional relationship to science, which on the one hand helped to define a distinction for some aspects of design, but on the other hand created an artificial divide that continues to this day (Kimbell 
2009). While this was useful at the time it currently does not bear up to closer examination and is unhelpful for bridging divides between the domains of thinking as suggested by Snow.

In 1978 Bruce Archer at the Royal College of Art (RCA) published 'Time for a Revolution in Art \& Design Education' (Archer 1978) as part of his Philosophy for Design developed from a series of lectures and a 2year research project in 1973 for the secretary of state for education. He proposed a third area of education recognizing that this line of thinking could be traced back from William Morris to Plato. Furthermore, he relied on C.P. Snow's two cultures, as the definition of two oppositional modes of intellectual enquiry without picking up on Snow's hints of the possibility of a third culture and what its attributes might entail.

Archer's original research project at the RCA was to explore design as a special branch of science, but as Boyd Davis's (Boyd Davis and Gristwood 2016) re-reading of his original doctoral thesis (lost and eventually found in the British library) reveals, this was unsuccessful and showed that Archer was also interested in more constructivist models of design influenced by his time at the Ulm school via Tomas Maldonado, Gordon Pask and Horst Rittel. Archer's attempt at developing design as a special branch of science recalls Buckminster Fuller's 1927 call to develop an industrially realizable design science (Fuller 1992) through his 'Eight strategies for a comprehensive anticipatory design science'. Although when we now look back at this proposal which was visionary in its time, the completist motivation and solutionist thinking can now seem even more unachievable in light of increasing knowledge and data mapping of complex dynamic problems, and the development of complex black box technologies, for example AI.

Archer described the substance of the third mode of intellectual enquiry for education as 'design thinking' having previously rejected the names 'technology' or 'technics' and 'aesthetics' for the new domain. Presumably these were considered to be already heavily associated with one of the other two domains. He also described the route for the three R's (Reading, Writing and 'Rithmetic) coming from Sir William Curtis MP in 1807 (Timbs and Limbird 1825) representing the monopoly the church at that time had on education and that Archer's great aunt fiercely protested and counter-proposed:

1. Reading and writing

2. Reckoning and figuring

3. Wroughting and wrighting

By wroughting she meant knowing how things are brought about, which we now call technology. By wrighting she meant how to do it, which we would now call craftsmanship. (Archer 1978, 4)

Simplistic though these 'R's may seem as attempts to encapsulate core domain level practices they do have a rather neat relationship to the humanities (reading and writing), the sciences (reckoning and figuring) and design thinking (wroughting and wrighting) as the practices and modes of intellectual enquiry. Whilst the first two modes of enquiry and knowledge gathering may be familiar the last set may not. In applied design thinking terms a closer definition could be that wroughting can be thought of as shaping, forging, moulding and producing parts or components whereas wrighting is the assembling, testing, adjusting and refining of the collective parts or assembly of the project. Furthermore, both may be acceptable as practices across a whole range of design disciplines from industrial design (components are wrought and product assemblies and wrighted) to architecture (plans are wrought and buildings are wrighted) visual communications (messages and brands are wrought and artwork is wrighted), service design (user journeys and stakeholder maps are wrought and experiences are wrighted) and fashion design (the pattern is wrought and the toile is wrighted). Archer went on to develop his enthusiasm for wroughting and wrighting as a precursor for what we now call 'Thinking Through Making' as a form of intellectual development that correlates with Schon (1983) and also described in various forms more recently by Sennett (2008) and Ingold (2013). This also develops one of the defining characteristics of design thinking, that knowledge is for transformation, for wroughting and wrighting the world by thinking through actions rather than thinking for actions. In this form knowledge can be compared to that described by Glanville (2005) as 'knowledge of', which he connects to the sciences. Scientists know about things that have happened, whether they are experiments or observed events, verses design that generates 'knowledge for' future transformation gained via the core practices of wroughting and wrighting through tacit and cognitive interchanges. Earlier Simon (1969) also defined design as having a form of future focused knowledge using the term 'what ought to be' as opposed to the sciences 'what is': 
Design, on the other hand, is concerned with how things ought to be, with devising artefacts to attain goals. We might question whether the forms of reasoning that are appropriate to natural science are suitable also for design. (Simon 1969, 115)

However not everyone holds that design thinking is a concrete and accepted third culture. New and Kimbell (2011) critique the abstracted separation between design and science while Ghassan (2016) makes a good case that design thinking should be reconsidered on a number of levels in light of reviewing Rowe's original work (1987). He indicates that designers often employ scientific thinking, the politics of STEM funding, and quotes the 'straw men' caricatures of science, a domain that often reveals more designerly affinities when investigated in more detail. He goes on to critique the way that design has set up scientific thinking as contrary, positioning it as an oppositional thinking domain or even a barrier for the progression and development of design thinking itself.

The lure of the third culture has continued to fascinate. Alternative positions on the third culture includes Brockman's 'The Third Culture' (1995) that revisits Snow's suggestion of a third culture of thinking by repositioning intellectual scientific contributions that strongly emerged in 1980-90's suggesting that these are the emergence of a third culture. Scientific research and breakthroughs in physics, biology and evolution have opened up more profound question on the nature of being and emergent intelligence in systems amongst a range of ideas. In the introduction evolutionary biologist Steve Jones suggests:

The best way of assessing the "third culture" idea is to ask, "Has there ever been more than one culture?" That's the central question. Is learning divisible or is it seamless? From 1550 to around 1950 the answer was obvious: culture is culture - (Brockman 1995, 24)

Asking whether learning, hence knowing, is divisible recalls Simon's 'what is' and 'what ought to be' and in parallel Glanville's 'knowledge of' and 'knowledge for' (2005) locating science and design into different time-based knowledge modes. It seems the questions of the core practices that may define a domain are not addressed directly here although the shift of science into intellectual and philosophical areas does correspond with Snow's requirement that the third culture is on speaking terms with the others and in many ways is an effort to bridge the intellectual gap. This illustrates a potential intellectual space for collaborative goals between domains. Kevin Kelly (1998) described Brockman's third culture as a 'streetwise science culture' and goes on to propose technology as the third culture, an idea considered and rejected by Archer more than two decades earlier. However, it is clear that in this context Kelly sees the third culture as an applied entrepreneurial culture external to the academic.

Pugh (1982) proposed the complete integration into one body of thinking as proposed by Leavis (1962), however it is unclear how this could work while supporting diverse core practices. In 'The In-Discipline of Design' Annie Gentes (2017) proposes bridging the gap between the humanities and engineering with a pluridisciplinary approach which proposes the reflectiveness of the humanities in supporting design as the connective medium between both areas as an agent of multidisciplinary. Design is again positioned between the sciences and arts and humanities as the connector between cultures of thinking.

Design thinking has a claim to be the third culture of thinking but there are also counter proposals and diverse positions within which design and other cultures of thought find themselves. Table 1 uses Archer's modes of enquiry to draw together thinking so far and tests the relationships between the core practices and knowledge types combining Simon and Glanville's positioning of knowledge types into temporal relationships. In addition, the table also proposes a position for the art and humanities which neither addressed. This is built upon later in the functions defined by the three domains of thinking and forms the foundation for underpinning a concluding collaborative positioning of the cultures and practices of the three cultures in relation to knowledge transformation.

Table 1. Structuring domain relationships of practices and thinking modes based on Archer's modes of enquiry.

\begin{tabular}{|c|c|c|c|}
\hline Domain & Science & Design & Arts \& Humanities \\
\hline
\end{tabular}




\begin{tabular}{|l|l|l|l|}
\hline \multirow{4}{*}{ Kore practice } & $\begin{array}{l}\text { Reckoning and } \\
\text { figuring }\end{array}$ & $\begin{array}{l}\text { Wroughting and } \\
\text { wrighting }\end{array}$ & Reading and writing \\
\cline { 2 - 4 } & $\begin{array}{l}\text { Knowledge of the } \\
\text { past, what has been } \\
\text { (Glanville, } \\
\text { Knowledge of, Simon } \\
\text { what is) }\end{array}$ & $\begin{array}{l}\text { Knowledge for future } \\
\text { transformation } \\
\text { (Simon, What ought } \\
\text { to be: Glanville, } \\
\text { Knowledge for) }\end{array}$ & $\begin{array}{l}\text { Knowledge for the } \\
\text { present }\end{array}$ \\
\cline { 2 - 3 } & $\begin{array}{l}\text { Generating the } \\
\text { fundamental } \\
\text { knowledge of the } \\
\text { environment and } \\
\text { technologies }\end{array}$ & $\begin{array}{l}\text { Proposing future } \\
\text { possibilities between } \\
\text { society and } \\
\text { technology }\end{array}$ & $\begin{array}{l}\text { Creating current views } \\
\text { of human activity in } \\
\text { the world }\end{array}$ \\
\hline
\end{tabular}

Since C.P. Snow's two cultures Rede lecture discussion has focussed on three different areas ranging from cultural separations in academia, the relationships of the sciences to other cultures, and finally the focus that we draw on here which considers design as the third culture and ask what is its relationship and potential contribution to the other cultures of thinking, and how might the collaboration of these cultures contribute to future global issues in a governed model?

The question remains as to how design relates to other domains, its collaborative position and the value of its future-projective 'knowledge for' leveraged through the core practices of wroughting and wrighting. In order to develop this further, the relationship of design's position to other domains, core practices, knowledge types and thinking culture require a structuring in the global ecosystem of governing knowledge and practices. In particular an exploration of how the collaborative governing across domains of thinking may be achieved and which concepts of governing are valuable.

\section{On design for governing and governing design}

Governing has drawn inspiration and lessons from many bodies of knowledge and some value can be gained by exploring how different forms of thinking, and the emergence of domain level thinking has supported this activity. It can also be useful to consider the relationship of governing with domain level practices.

When considering the governing of large organization, nations and states we can examine the historical education and training of great leaders to get a sense of their thinking domains. We know for example that King Henry VIII's (1491-1547) syllabus included languages, grammar, theology, history, rhetoric, logic, philosophy, arithmetic, literature, geometry, music, and that he was influenced greatly by astronomy, navigation and cartography. The great Qing dynasty emperor Kangxi (1654-1772) regarded by some as the most learned Emperor in Chinese history embedded himself in education so he could rule with knowledge gained from historical perspectives including calligraphy, Confucianism and medicine. However, for both Henry VIII and Emperor Kangxi we can see subjects like mathematics, astronomy, navigation and medicine that to the contemporary thinker could be categorized as scientific subjects. Yet in their time these were used as tools of measurement for example in warfare and financial plans and they were not considered as subjects from which one could learn lessons thinking modes for governing. Many of these subjects contained elements of religious and cultural beliefs along with superstitions and they also existed before the emergence of the scientific domain. Examples of the types of tactical and strategic text that would have been read by rulers include Sun Tzu's the Art of War (500 BCE; Sun-Tzu 1964), Machiavelli's The Prince (1513). Hobbes Leviathan (1651) and later Von Clausewitz's On War (1832) which all sought to give practical methods for governing, strategy and politics of warfare for 
ruling elites based on historical experience. We can consider the value and role of these subjects in relation to their context. For example, governing during this period required rulers to learn how to act based on recorded precedents of what had come before. Historical precedent was a good way to apply known experience of the past to solving present day situations.

These were tried and tested paradigms recorded from the past to cope with the present for rulers in a world where the amount of taxes raised at the next harvest could fund another military campaign for defence or to gain land, power and further income potential. Lessons from past historical events were a good match for the relatively short-term issues of the day as the future was very close, not more than six to twelve months away. Towards the 18th and 19th centuries the tradition of governing via lessons learnt from historical precedent became challenged by the industrial revolution as new technologies of communication, warfare and travel alongside economic revolutions interrupted the status quo and the economic models of governing. The new emerging challenges could not always be tackled using lessons from the past espoused by Smith's macro-economic top-down 'guiding hand' (1776). As new technologies accelerated and disrupted societies, communications, power relations and access to new knowledge upset stable economies. Creative destruction (Schumpeter 1943) emerged as a complex cycle of technologically mediated change. This opened up an understanding that the responses of the past were increasingly unlikely to support the new asymmetrical challenges of the future. In other words, we could expect that a new form of thinking, possibly scientific thinking would be in the ascendancy and understanding the impact of technology could provide better leadership. The future was getting more complex and further away as technologies needed investment and development often resulting in wicked problems and unforeseen consequences as a historical mind-set increasingly struggled to tackle the disruptive impact of increasingly complex technologies on society.

Another form of governing was described by James Clark Maxwell in 'On Governors' (1867). Ostensibly Maxwell's focus was on describing the mathematical and engineering model for governing steam pressure vessels and other mechanical systems. Steam pressure vessels obey the second law of thermodynamics (incidentally the second law was cited by Snow in his 1959 Rede lecture claiming that many literary intellectuals were unaware of it [Furedi et al. 2009, 1]) where systems tend towards chaos. The role of governors is to use a centrifugal physical counterbalance to open and close a value in order to reduce steam pressure and bring the system back into balance. Ashby developed this first order cybernetic principle of governors into early second order cybernetic work on the black box and feedback loops (Ashby 1956) showing how a complex 'unknowable' system could be both observed and acted upon by an observer who recognizes their own dual agency in the system via inputs and outputs. Glanville (1994) developed a strong body of work that showed how second order cybernetic concepts were highly aligned with design practices connecting systems theory into tangible design outputs. Crucially this dealt with variety in design and how designers can generate variety in systems so that they have the requisite amount of variety (Ashby 1958). In other words, generating an equal or greater number of potential control states (design methods, concepts, proposals etc.) compared to the potential number of states that a system could find itself in. This model can also be applied to creative systems driven by design (Hall 2016) and how they create knowledge for future transformation and towards the improved tackling of wicked problems. Wroughting and wrighting are the core design practices that develop new products and services that change the future states of systems. It could be argued that the future knowledge for transformation role of design is to ensure that it continues to generate more states (creative solutions) than the potential number of future states (issues) that might arise. Collaborating in observing and acting in a system across domains could address some of the wicked problems of the Anthropocene by integrating top down and bottom up issues.

We can also see the emergence of design at governmental levels in a series of more recent developments. While many countries have policies for engaging design at a national level there is some evidence of design thinking to support governing. In 2010 the mayor of Seoul (Nominated by the World Design Organisation as Design Capital 2010) Oh Se-Hoon, declared that 'Design is everything' (Design Council 2010) and appointed Kyung Won Chung as design Czar, a role equivalent to deputy Mayor. Chung used his position as head of culture design and tourism to use design thinking as a strategic governing strategy enhancing many aspects of the city including quality of life. Initiatives including the Seoul Design Centre, Seoul Design Olympiad event and the Greenways project brought design via governing the city infrastructure development. 'Designomics' was a phrase promoted by Chung to align design value with economic growth in the city. Design was used as a method for improving the city infrastructure and by 
extension improving social conditions. In terms of core design practices design is clearly wroughting through new projects with an intention to wright social improvement. In this context design is used in its traditional form of material practice, it is doing what it is good at serving governing, whereas design thinking could function as governing.

The All Party Design Innovation Group (APDIG 2017) supported by Policy Connect provides evidence of the emergence of the recognition of design by cross party parliamentarians who are applying design thinking to UK government policy on issues as diverse as IP, Education, public service reform, international competitiveness etc. Interestingly APDIG is a cross-party group of parliamentarians indicating that design may be an emerging cross-cutting form of thinking that is gathering interest in the political realm and indicates an ambition beyond design delivering solutions impact. Design thinking and its practice of 'wroughting and wrighting' may yet be seen as an emerging mode supporting governing after 'Thinking, Making, Testing: A manifest for design' led by Lord Rogers promoted design thinking at the heart of government (Rogers et al. 2017). It recommends 'understanding the application of science and technology, particularly in addressing challenges of the environment and society' (5) thereby employing Snow's requirement to bridge the gap between technology and society.

However, one of the characteristics of this and some other reports is to promote and position design in terms of its ability to deliver by boosting its tactical role rather than its potential strategic function as a mode of thought leadership. In this respect design's promotional ability to deliver applied impact is both a benefit and a hindrance. It provides plenty of examples through creative methods of positive impact which on the one hand is natural promotion material for its value, but on the other hand this diminishes its potential strategic value across domains. Design Policy Monitor goes further and examines global efforts to establish design policies in different countries and while the focus is mainly on policies for design it does note that:

Governments will develop their internal capabilities for design- driven innovation by training staff in design methods, employing design managers and establishing multi-disciplinary innovation units. (Whicher, Swiatek and Cawood 2015, 4)

While this is not specifically clear about a policy for design or the design delivery of governing as opposed to policies through design, it can encompass both. More recently the Bureau of European Design Associations (BEDA) Policy Lab announced an insight forum on 'What is the future of design for policy making?' (BEDA 2017) indicating a growing interest in design for policy and governing.

The lack of positional clarity and design's strategic domain level issues along with it being such a good applied solver of problems is potentially an obstacle for being recognized as a mode of governing. A central issue is whether current practices in design disciplines are holding back design thinking. Are the practical bottom-up delivery mechanisms of daily design practice really suitable as a model to be adopted for governing and are there other ways of thinking through making that can escape these limits? Even though Sennett (2008) and Ingold (2013) have both tried in different ways to promote the purer value of thinking through making (wroughting and wrighting) as an equivalent form of enquiry to writing to performing and arithmetic, the examples and methods described are limited. Design may be critically constrained by falling back on its classic preoccupation with delivering a result as opposed to reframing the conversation about the future. It may not have broken free from describing itself as a discipline instead of a mode of thinking as confirmed by the Rogers report which still sees design through a disciplinary lens preoccupied with making things described as a profession instead of how it may be a form of governing. This may also point towards design occupying a different set of relationships while still being a third culture of thinking.

It appears that there is a gap between design thinking being considered as a form of governing as illustrated in the earlier historical examples and its capacity to make changes for the future which is often an aim of governing, if not its over-arching mandate. Governing in the political sense verses governing of a system by balancing inputs and outputs to enable a system to remain in balance. A further challenge lies in collaborating different core domain practices that generate different types of knowledge.

\section{Inter-Domain collaboration}


The contemporary challenges we currently face are neither those of a medieval king, nor a renaissance era emperor, and neither are they those of a 19th century industrial revolutionary. Our contemporary challenges are not clearly defined, nor can they be answered by our current modes of thinking and collaborative knowledge. Design's ability to generate knowledge for future transformation through the practices of wroughting and wrighting recommend it for collaboration with the sciences and art and humanities particularly in light of its future transformation capacity.

A manifesto for governing with design thinking may cite its ability to tackle wicked problems and mediate in technology development towards a sustainable 'human led' model. It would define its position as the fluid connecting partner as per Snow's suggestions bridging the space between the sciences and humanities for mediating and guiding fundamental discoveries and new technologies focussed on sustainable human needs gained from a social perspective. John Maeda who shares both a scientific and creative background captured this synthesis:

With all that we have to address in the world - warming continents, fluctuating economies, monstrous cities - pursuing scientific questions in tandem with artists and designers may not seem like conventional wisdom. But given the unconventional nature and scale of the problems we face today, there is real value to be gained from collaborations that bridge the best talents we have in both the qualitative and quantitative domains. (Maeda 2013).

Maeda's suggestion points towards design's collaborative and connecting capability. Crucially design thinking can also add variety to the problem space (Hall 2016) deploying its manifesto aims via wroughting and wrighting wicked global problems to increase the number of solutions being considered. At the heart of design's potential as the third culture is the theoretical possibilities of wroughting and wrighting operating in conjunction with reading and writing, and reckoning and figuring to provide a powerful triangulation of domain level practices spanning all forms of knowledge of the past, present and for the future.

The diagram in Figure 1 proposes the collaboration of the core practices of the Sciences (figuring and reckoning), arts and humanities (reading and writing) and design (wroughting and wrighting)

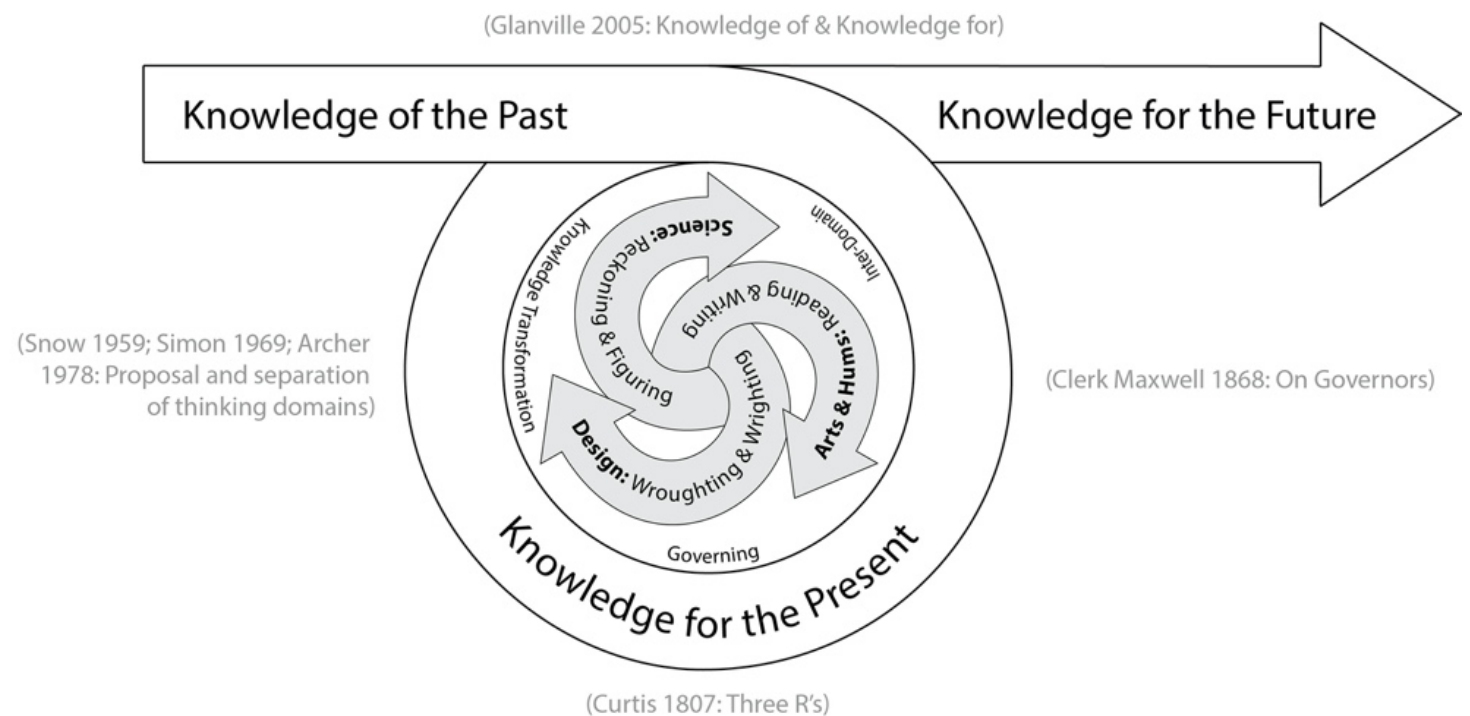

\section{Collaboration of Inter-Domain practices governing the transformation of knowledge from past to future}

Figure 1. Collaboration of inter-domain practices governing the transformation of knowledge of the past towards knowledge for improving the future. 
in order to tackle wicked problems (Rittel and Webber 1973) and the issues of the Anthropocene by connecting scientific knowledge (past), arts and humanities knowledge (present) and design's capacity for developing knowledge for future transformation. In this sense, the governing model transitions design as a third culture of thinking into an interdomain space retaining both its capability for generating knowledge for future transformation alongside knowledge of the present (arts and humanities) and knowledge of the past (from the sciences). The governor for this system is positioned across all three domains as they collaborate practices through the feedback loops of core practices and knowledge transformation thereby identifying issues of today linked to addressing challenges of the future.

Some might question the relegation of knowledge to temporal phases and this deserves more explanation. A scientific experiment is concluded and then it is reported, and the same can be said for observational reporting in science. The thing that is observed has happened, and we construct meaning, theories and concepts to explain what we have seen. The thing has been, and our knowledge of this 'past' provides crucial foundational knowledge of principles, materials and processes ripe for future technological application. We figure and reckon that which is past and we construct it as an after- event. Effectively this knowledge is owned in the past. The arts and humanities also deal with the past, however this past is owned in the present, it cannot be owned in the past as it is formulated, read and written in the present context. It may change the future as may scientific thinking, however it is owned in the present. Design is forever propositional, it proposes new things to change the future without fully knowing the future. Design knowledge is for future transformation and it is forever ahead of us even though it is created in the present, it is owned in the future forever. Another way of considering these knowledge relationships between domains is to con- sider them from a human driven perspective; by humans (science), about humans (art and humanities), for humans (design). One could argue that none of these modes of thinking are possible without the other, yet they rarely 'see' each other's domains. The aim of the proposition made here is to encourage the seeing, and to link core practices to govern collaborations forming effective cultures of knowledge transformation.

Science has shown us the Anthropocene, (Waters et al. 2016) however, science is not the answer. It is part of the answer but not the whole. The Anthropocene is not specifically an issue in itself, it relates to the observation of passing from one geological epoch into another and contains within this a subset of circumstances which severely limit our ability to sustain future survival. Design is already addressing this, however there is confusion between illustrating some of the issues (Anderson 2015) verses addressing the issues without the limits of a solutionist mindset. 'Knowledge of' is crucial for tackling future issues in providing foundational principles and thinking, yet its 'past' ownership does not allow it to address the future via the present. Design is knowledge for future transformation yet its future ownership disallows its use without also collaborating with 'knowledge of' the past via the present. In classic wicked problem terms, we aim to improve the problem, something described by Simon as 'Designing without final goals' (Simon 1969, 162). The aim of collaborating inter-domain thinking via governing core practices is to address these shortcomings to transform knowledge into delivering preferred futures (Bezold and Hancock 1994; Voros 2003).

\section{Conclusions}

The terms 'wroughting and wrighting' are successful negotiators for design as a third culture of thinking that generates knowledge for future transformation by bridging the gap between the social and the technological. It may be considered as Snow's illuminating characteristic of a third culture of thinking being on speaking terms with both the sciences and also the arts and humanities. Design thinking can be part of a domain collaboration for addressing the special set of global wicked problems contained within the Anthropocene by triangulating its core practices and knowledge forms supporting the idea that delivering mass change is not just an interdisciplinary issue, it is inter-domain thinking issue. Ultimately the question of how we should recognize the differences between domains of thinking becomes superseded by our current situation and the real issue becomes those of inter-domain collaboration.

As national governments move from STEM (Science Technology Engineering Mathematics) to STEAM (Science Technology Engineering Arts Mathematics) in order to deliver the creative and human centred inputs necessary to ensure global sustainability, design as the third culture can play a role in collaborating the governing of knowledge exchanges to balance future sustainability by creating the requisite variety between 'knowledge of' and 'knowledge for' transforming the future. The collaboration 
of inter-domain practices governing the transformation of knowledge of the past towards knowledge for improving the future aims to structure the ideas discussed on the arc stretching from Snow through Archer, Maxwell, Ashby and Simon to Glanville. It aims to frame a model for inter-domain collaboration while at the same time position the core practices of design as the third culture of thinking for improving (Kolko 2012,10) the wicked problems of the Anthropocene.

\section{Disclosure statement}

No potential conflict of interest was reported by the author.

\section{References}

Across Parliamentary Design Innovation Group (APDIG). 2017. Accessed 9 October 2017. http://www.policyconnect.org.uk/apdig/ node/1.

Archer, Bruce. 1968. "The Structure of Design Processes." PhD diss., Royal College of Art, London, Shelfmark: Document Supply DRT 484530. Available on Ethos: http://ethos.bl.uk/OrderDetails. do?uin=uk.bl.ethos.484530.

Archer, Bruce. 1978. Time for a Revolution in Art \& Design Education. RCA Papers: 6. London, UK: Royal College of Art.

Anderson, Kayla. 2015. “Ethics, Ecology, and the Future: Art and Design Face the Anthropocene." Leonardo 8 (4): 338-347.

Ashby, W. Ross. 1956. An Introduction to Cybernetics. London: Chapman \& Hall, Chap. 6, The Black Box: 86-117. doi:10.1177/ 003172170408600105.

Ashby, W. Ross. 1958. “Requisite Variety and Its Implications for the Control of Complex Systems.” Cybernetica (Namur) 1 (2): 83-99.

BEDA. 2017. "What is the Future of Design Policy Making?" Policy Labs, Accessed 29th October. http://www.beda.org/all-news/pol- icy-labs-what-future-design-policy-making-0

Bezold, Clement, and Trevor Hancock. 1994. "An Overview of the Health Futures Field, WHO Consultation." Healthcare Forum Journal Mar/April: 23-29.

Boyd Davis, Stephen, and Simone Gristwood. 2016. “The Structure of Design Processes: Ideal and Reality in Bruce Archer's 1968." PhD diss., Design Research Society, Brighton, June 27-30th.

Brockman, John, (1832). 1995. The Third Culture. Simon and Schuster: The University of Michigan.

Clausewitz, Carel von Michael Howard, Peter Paret, and Bernard Brodie. 1984. On War. Princeton, N.J.: Princeton University Press.

Cross, Nigel. 2011. Design Thinking: Understanding How Designers Think and Work. Oxford, UK: Berg Publishers.

Fuller, Buckminster. 1992. Cosmography. USA: Hungry Minds.

Furedi, Frank, Roger Kimball, Raymond Tallis, and Robert Whelan. 2009. From Two Cultures to No Culture - C.P. Snow's ‘Two Cultures' Lecture Fifty Years On. Trowbridge, Wiltshire: The Cromwell Press.

Hall, Ashley. 2016. Designing Creative Destruction. Brighton, UK: Design Research Society.

Gentes, Annie. 2017. The In-Discipline of Design: Bridging the Gap between Humanities and Engineering (Design Research Foundations). 1st ed. Springer. doi:10.1007/978-3-319-65984-8.

Ghassan, Aysar. 2016. Design Thinking: A Rod for Design's Own Back? Brighton, UK: Design Research Society.

Glanville, Ranulph. 1994. "Variety in Design.” Systems Research 11 (3): 115-128. doi:10.1002/sres.3850110307.

Glanville, Ranulph. 2005. “Design Prepositions.” In: The Unthinkable Doctorate, 1-9. Brussels, UK and Australia: 
Cyberethics Research, American Society of Cybernetics.

Gooden, Henrietta. 2015. Robin Darwin: Visionary Educator and Painter. London: Unicorn Press.

Hobbes, Thomas. 1651. 1998. Leviathan, edited by Gaskin, J. C. USA: Oxford University Press.

Ingold, Tim. 2013. Making: Anthropology, Archaeology, Art and Architecture, United Kingdom: Routledge.

Kelly, Kelly. 1998. “The Third Culture, Essays on Science and Society.” Science 279 (5353):992-993. doi:10.1126/science.279. 5353.992.

Kimbell, Lucy. 2009. “Design Practices in Design Thinking.” European Academy of Management 1-24.

Kolko, Jon. 2012. Wicked Problems Worth Solving: A Handbook and Call to Action. Austin: Austin Centre for Design.

Leavis, Frank Raymond. 1962. (2013). Two Cultures? The Significance of C.P. Snow. New York: Cambridge University Press.

Machiavelli, Nicola, and David Wootton, (1513) 1995. The Prince. Indianapolis: Hackett Pub. Co.

Maeda, John. 2013. Artists and Scientists are More Alike Than They are Different, Scientific American, Accessed 12th January 2017. https://blogs.scientificamerican.com/guest-blog/artists-and-scientists- more-alike-thandifferent/

Maxwell, James Clerk. 1867. “On Governors.” Proceedings of the Royal Society of London, 16, 270-283.

New, Steve, and Lucy Kimbell. 2011. "Chimps, Designers, Consultants and Empathy a "Theory of Mind" for Service Design." In Proceedings of 2nd Cambridge Academic Design Management Conference, edited by Moultrie, James, Krista Keranen, Wei Liu, and Karen Miller. September, 139-152.

Pugh, Stuart. 1982. “Design-the Integrative-Enveloping Culture-Not a Third Culture.” Design Studies 3 (2): 93-96.

Rittel, Horst, and Melvin Webber. 1973. “Dilemmas in a General Theory of Planning.” Policy Sciences 4 (2): 155-169.

Rogers, Richard, Caroline Dinenago, Janet Whittaker, and Barry Sheerman. 2017. Thinking, Making Testing, All Party Design Innovation Group, Accessed 9th October 2017. http://www.policyconnect.org.uk/apdig/sites/site_apdig/files/report/514/fieldre- portdownload/manifestofordesign.pdf

Rowe, Peter. 1987. Design Thinking. Cambridge, MA: MIT Press. Scho€n. Donald A. 1983. The Reflective Practitioner: How Professionals Think in Action. New York: Basic Books. doi:10. 1093/sw/5.1.113.

Schumpeter, Joseph. 1943. Capitalism, Socialism, Democracy. Routledge: London and New York.

Sennett, Richard. 2008. The Craftsman. USA: Yale University Press.

Simon, Herbert. 1969. The Sciences of the Artificial. Cambridge, MA: MIT Press.

Smith, Adam. 1776. "An Inquiry into the Nature and Causes of the

Wealth of Nations." 1st ed. 1776, vol. II of The Glasgow Edition of the Works and Correspondence of Adam Smith, edited by R. H. Campbell, A. S. Skinner and W. B. Todd. (1976). Oxford University Press.

Snow, Charles Percy. 1959. (2013). The Two Cultures and Scientific Revolution. New York: Cambridge University Press. Introduction by Stefan Collini.

Sun-Tzu, Samuel Griffith, (500 BCE). 1964. The Art of War. Oxford: Clarendon Press.

Timbs, John, and John Limbird. 1825. The Mirror of Literature Amusement and Instruction, 5:85.

Timmons, William. 2007. Older Than Snow: The Two Cultures and the Yale Report of 1828. A Journal of the Oxford Round Table. Voros, Joseph. 2003. “A Generic Foresight Process Framework.” Foresight 5 (3): 10-21. doi:10.1108/14636680310698379.

Waters, Colin, Jan Zalasiewicz, Colin Summerhayes, Anthony D. Barnosky, Clement Poirier, Agnieszka Gałuszka, Alejandro Cearreta., et al. 2016. "The Anthropocene is Functionally and Stratigraphically Distinct from the 
Holocene." Science (6269): 351. doi:10.1126/science.aad2622.

Whicher, Anna, Piotr Swiatek, and Gavin Cawood. 2015. Reviewing Innovation and Design Policy Across Europe, Design Policy Monitor, Accessed 29th October 2017. http://www.icod.org/database/files/library/SEE_DPM_2015_Jan.pdf

\section{Biography}

Ashley Hall is a professor of Design Innovation at the Royal College of Art in London and a visiting professor at the Central Academy of Fine Arts in Beijing. He leads postgraduate research in the Design School and MRes Healthcare Design. He researches on innovation 